\title{
VISUAL PATTERN-DISCRIMINATION IN THE VERTEBRATES: III.-DIFFERENCE-THRESHOLD FOR BAND-WIDTH IN THE MONKEY AND THE DOMESTIC CHICK.*
}

By H. M. Johnson.

IN the experiments reported in the above series of papers, the general procedure observed is that of the so-called "discrimination-method" of Professor R. M. Yerkes. In brief, the animal is placed in a chamber in which his movements may be controlled and observed, and allowed to obtain food in one of two food-compartments. The entrance to each compartment is marked with a visual object. These objects are mutually interchangeable, and may be made to differ in any physical characteristic-e.g., area, outline, brightness, color, etc. One of these objects, the "positive stimulus," indicates the food-compartment to be chosen; the other, called the "negative stimulus," indicates the food-compartment to be rejected. If the animal chooses the box indicated by the negative stimulus he receives a light electric shock, automatically given. The left-right position of the stimuli is determined by a pack of shuffled cards containing an equal number of reds and blacks. Numerous well-known precautions described in Papers I and 2 of this series $\rightarrow$ are taken to prevent other factors than the visual stimulus difference under study from becoming effective.

In the beginning of the work on a given problem the stimulusdifference is made sufficiently large for the animal to acquire a "perfect discrimination-habit"-i.e., of choosing the positive stimulus in 90 per cent. to IOo per cent. of a large number of trials. The difference is then decreased by very small steps until a point is found where the percentage of correct choices is about 75 -i.e., where the stimulus-difference is effective in half the total number of cases. This point is called the animal's threshold.

In the present work the stimuli are prepared by two Ives-Cobb visual acuity test-objects, so constructed as to present two fields, respectively, equal in area, outline, color, and mean brightness. Each field is covered by a system of alternate dark and bright striæ, respectively, equal in width, and the width and direction of the striæ may be independently varied.

* To appear in Journal of Animal Behavior.

$\dagger$ Journal of Animal Behavior, vol. 4, p. 319 ff., 1914. 
In a preliminary experiment the direction of both systems was made horizontal, and the width of each band on the negative field was made about 0 .I mm. (The animal was restrained from bringing the eye nearer than $60 \mathrm{~cm}$. from the test-object, at which distance the negative field was of sensibly uniform brightness to the human eye.) Each of the bands on the positive field was made $2.23 \mathrm{~mm}$. wide until a perfect discrimination-habit was established, after which band-width was reduced by small steps until the threshold was found for each animal. For the one Capuchin monkey used in this work this value was $0.163 \mathrm{~mm}$., each band subtending a visual angle of $57^{\prime \prime}$. (The mean value obtained for five photometrists was $49^{\prime \prime}$, with an individual mean value of 2 per cent. to 4 per cent.) For two Indian game cocks the bandwidth was a little over $0.7 \mathrm{~mm}$., subtending a visual angle of a little over $4^{\prime}$ at the distance given. Two dogs failed to establish a discrimination-habit, although the band-width on the positive field was about $4 \mathrm{~mm}$. These results served to determine the range of stimulus-values in which the present tests could be made.

In the work herein reported both systems of striæ lay in the horizontal direction, and the band-width on each field was above the animal's stimulus threshold; stimulus-difference under study was the band-width and conversely of number in the positive and negative systems, respectively. The animals were fed at the coarser system and shocked at the finer system.

Chick I failed to learn the problem. He succeeded, however, in maintaining perfect discrimination when the two systems were opposite in direction and also different in band-width, but he failed when either factor was eliminated.

Chick 2 was tested at six points between absolute band-width of $3.1 \mathrm{~mm}$. and $0.74 \mathrm{~mm}$. The thresholds yielded varied between 33 per cent. and 42 per cent. of the value of the "standard" stimulus. No consistent rule of variation was discovered.

The monkey was tested at seven points for the "upper" and "lower" threshold values, between $\mathrm{I} .56 \mathrm{I} \mathrm{mm}$. and $0.173 \mathrm{~mm}$. His results are quite consistent. At the standard stimulus-value $0.3 \mathrm{I} 2 \mathrm{~mm}$. the threshold was less than 3 per cent.; at $0.223 \mathrm{~mm}$., about 5 per cent., and at o.I9I mm., 9 per cent. At stimulusvalues larger than 0.3 I $2 \mathrm{~mm}$. the thresholds were much larger, but they were obtained in the early stages of experimentation, and a later test revealed that the differences were due to a practice-effect.

Vor. CLXXX, No. 1076-18 
A subsequent test gave a mean of the upper and lower thresholds at standard stimulus- $0.780 \mathrm{~mm}$. of less than 3 per cent.

The final values given by the monkey, when plotted against stimulus-values, gives curves which closely approximate those yielded by two human subjects, in rather rough tests, made under identical visual conditions.

A discussion of these results in the light of comparative anatomy and physiology will be attempted in a later paper.

Polluted Farm Waters. (U.S. Geological Survey, Water Supply Paper 255.) - In selecting a country home for the summer special attention should be given to the question of a pure water supply. Farms, which are generally remote from towns, cities, or other areas of congested population, seem to be almost ideally situated for obtaining pure and wholesome water. In reality, however, polluted water is exceedingly common on farms, and typhoid-fever rates are usually greater in country districts than in cities. Typhoid fever is transmitted largely in drink or food taken into the stomach, and is especially likely to be communicated by polluted waters obtained from shallow wells near spots where the discharges of typhoid patients have been deposited and subsequently carried into the wells, and it is doubtless principally this fact that makes the disease so common in farming regions.

The sources of the water used on the farm are numerous-lakes, streams, springs, wells of various kinds, and cisterns-all being extensively used, although the water from lakes and streams is generally used only for stock. Each of these sources under some conditions may yield entirely safe and satisfactory supplies, while under other conditions certain of them may be a constant menace to health.

Of the various sources of water supply, the ground water is the most satisfactory for farm use, because it is least liable to pollution, and streams and pools are the most unsatisfactory, because of the ease and frequency with which they are contaminated. Fortunately, however, they are very seldom used for drinking and domestic purposes, being utilized mainly for stock, on which the effect of slight general pollution is not serious, though some severe epidernics of disease among cattle have been traced to polluted streams. The underground supplies, whether from wells or springs, although safe in many localities, are far from being universally so, the safety depending mainly on their location and on the nature of their protection.

Many of the failures to protect adequately the water supplies used for drinking arise from a lack of knowledge of the manner in which waters circulate through the ground and of the ways in which they may become polluted. 